EDITORIAL

\title{
Why College Faculty Need to Know the Research about Learning
}

\author{
Gary A. Smith, PhD \\ Director, Office for Medical Educator Development \\ Professor, Organization, Information, and Learning Sciences \\ University of New Mexico
}

\section{When the Recipe Fails}

Imagine trying a new cookie recipe. You obtained the ingredients and instructions from a trusted friend who received glowing accolades when serving this dessert. Looking forward to the same success you bake a batch with very different results. The cookies are oddly shaped, somewhat burnt, and have a nasty taste an inedible outcome. Discouraged, you throw away both the cookies and the recipe, destined to maintain your comfortable, if somewhat bland, baking repertoire.

How does this vignette of baking disaster relate to teaching? Consider for a moment those higher-education faculty who are encouraged to adopt interactive, learner-centered pedagogies in place of their existing didactic, teacher-centered practice that feels comfortable and yields consistent results. They learn of successes with interactive learning from others at their institution, through workshops, or from the scholarship of teaching and learning (SoTL) literature. Nonetheless, these faculty undertake great effort to change their instructional approaches only to be met with failure. Not only are they discouraged from further attempts to transform teaching and learning but colleagues who are skeptical of progressive teaching approaches gladly point to these results as contrary evidence to ambiguate arguments to change centuries-old traditions in teaching.

What if, instead, you were more knowledgeable about baking; not an expert chef but with an interest to understand the tenets of cooking that build selfefficacy to explore the challenge of an unfamiliar recipe? Looking back at the failed cookies you might diagnose a number of choices and errors that could, singularly or in combination, account for the unpalatable outcome. Was a necessary highaltitude correction neglected? Was it inappropriate to substitute margarine for butter? Did the short cut of setting the oven to a higher temperature contribute to the undesired results? Did you overbeat the dough?

In a decade of observing classroom instruction as both a faculty developer and a researcher, I have encountered many teachers who match with the first vignette but far fewer who resemble the baker in the second scenario. When adapting a teaching innovation, even in consultation with expert instructors, many teachers lack the knowledge to evaluate and understand the background to the recipe. The context of teaching - subject matter, student preparation and prior knowledge, physical classroom environment - may require modification to the teaching recipe just as the cookie dough required a different ratio of ingredients for a high-altitude kitchen. Care must be taken, however, not to make modifications that diminish the learning impact. Most commonly, these deleterious changes include substitutions and short cuts - comparable to margarine and a higher oven setting - that are contrary to the cognitive processes intended by the pedagogy. In

It is unreasonable to expect all college professors to have learningscience expertise but what must they know about evidence-based and research-informed teaching and learning in order to successfully implement unfamiliar pedagogy? addition, the implementation of a teaching innovation usually involves more than the explicit knowledge of written instructions but also involves tacit knowledge, which requires observation; analogous to the vague instruction of knowing when the dough is sufficiently blended. It is 
unreasonable to expect all college professors to have learning-science expertise but what must they know about evidence-based and research-informed teaching and learning in order to successfully implement unfamiliar pedagogy?

\section{Best Intentions - Not the Best Results}

Higher-education writers commonly lament why it is possible that lecturing remains the dominant approach to teaching many subjects despite a rich research literature on the positive learning impacts that result from instead emphasizing active and socially interactive learning opportunities. The paradox is particularly true in science, technology, engineering, and mathematics (STEM) fields where a loss of majors impacts both degree completion and the widely perceived strategic need to develop a larger and more diverse STEM workforce (e.g., Carnevale, Smith, \& Melton , 2012; President's Council of Advisors on Science and Technology, 2012). Ironically, it is in these same STEM disciplines where most of the relevant research on pedagogies that affect learning has been conducted (see Kober, 2015, for a recent review), with funding from the National Science Foundation, National Institutes of Health, Howard Hughes Medical Foundation, and other public and private sources. The recent meta-analysis by Freeman et al. (2014) offers such a compelling view of the merits of replacing lecture with active learning in STEM courses that they draw a metaphorical comparison to pharmaceutical trials:

If the experiments analyzed here had been conducted as randomized controlled trials of medical interventions, they may have been stopped for benefit-meaning that enrolling patients in the control condition [lecture] might be discontinued because the treatment being tested [active learning] was clearly more beneficial. (p. 8413)

Innumerable authors explore the barriers to change in higher-education teaching (e.g., Austin, 2011; Henderson \& Dancy, 2007; Hora, 2012; McCrickerd, 2012; Sunal et al., 2001). Clearly, the matter of obstacles to adopting demonstrably effective teaching practices is a complex, multivariable problem with both individual and organizational components. It is not my intention to review or dispute these myriad interwoven webs that challenge progress on the wider sustained practice of research-based teaching methods. Instead, I focus on the teacher who wants to try something different, is at least partially if not wholly accepting of the relevant research, seeks out information and guidance, but does not succeed; see Henderson (2005) for an illuminating case study. It is these faculty, analogous to the first cookie baker, who could benefit most from colleagues in faculty development and SoTL because most or all other barriers to adoption have likely been surmounted.

Before exploring the cause of such failures it is important to acknowledge that higher-education faculty express strong interest in teaching and are knowledgeable, to some degree, about effective teaching strategies. The biennial faculty survey by the Higher Education Research Institute (HERI) consistently shows that $95-99 \%$ of faculty across the various institutional types identify teaching as a personally essential or very important component of their job; a rating that is significantly higher than for research or service (Eagan et al., 2014). If Henderson and Dancy's (2007) qualitative study of a sample of physics faculty is representative, then we can assume that college instructors hold views of the ineffectiveness of lecture in comparison to interactive pedagogies that are consistent with education research, albeit inconsistent with their actual practice. The HERI surveys over the past 25 years (available at http://www.heri.ucla.edu/facPublications.php) have shown an overall downward trend in the use of extensive lecturing in most classes (hovering just below $50 \%$ in the most recent surveys) while use of small-group learning during class and group projects have both more than doubled and exceed use of lecture. In addition, the 
prospects for continued changes are likely as younger faculty are promoted through the ranks in the wake of retirements; assistant professors consistently show less use of lecture (47.7\% in the 2013-14 survey) and greater use of small-group learning $(68.1 \%)$ than do full professors (55.3\% and $50.9 \%$, respectively).

The challenge of implementing research into practice is not unique to higher education but is also problematic in many aspects of health and human services, inspiring the scholarly field of implementation science (Fixsen, Naoom, Blase, Friedman, \& Wallace, 2005). Two of the many lessons learned from implementation science (Fixsen et al., 2005) are critically important to faculty developers and SoTL researchers. First, the dissemination of research results through peer-reviewed publications, mailings, and distribution of practice guidelines is, by itself, ineffective to induce change. The second key finding from implementation science is that training, no matter how well it is done, will not, by itself, lead to effective deployment of research-based innovations and interventions; i.e., the traditional faculty development workshop, alone, will not likely transform teaching to a great extent. Elaine Seymour (2002), a scholar of higher-education STEM reform, captures the essence of these findings by pointing out that there is no clear evidence that "good ideas, supported by convincing evidence of efficacy, will spread 'naturally'-that, on learning about the success of particular initiatives, others will become convinced enough to try them" (p. 92).

With these insights, let's now return to our critical question: What causes failure even when implementation of research-based instruction is accepted and attempted? Evidence for the lack of increased student learning through some utilization of active learning is more apparent in the literature than the proponents of such innovation commonly profess. In Richard Hake's (1998b) early and widely cited review comparing conceptual learning of introductory physics via interactive engagement versus lecture, it is apparent that the interactive pedagogy is capable of generating at least twice the learning of lecturing, but there are a handful of classes where the results are indistinguishable. Even in the bravado of the Freeman et al. (2014) analysis, concluding that, on average, failure rates in introductory STEM courses increase by more than $50 \%$ under traditional lecture conditions than under active learning, it is also notable that in a quarter of the studies failure rates differed by no more than 5 percentage points or were actually higher in the active-learning courses. Why aren't all faculty, and more importantly their students, experiencing the benefits of active learning?

\section{The Tacit Knowledge Problem}

I suggest that one critical implementation problem is the transfer of knowledge from the research arena to the classroom and from one innovative teacher's practice to another teacher. Central to this issue is the organizationallearning research by Ikujiro Nonaka, which distinguishes between explicit and tacit knowledge (e.g., Nonaka \& vonGrogh, 2009). Explicit knowledge is that familiar form of knowledge that we transfer to others through spoken and written word and illustrations. Tacit knowledge, on the other hand, cannot be articulated and is tied to sensed experiences, intuition, and implicit rules of thumb. If you pause to reflect for a moment, you will likely realize that much of what you do in your teaching cannot readily be described to a colleague; you might, instead, say "come to my class to see it and then I think you'll understand." There is a great deal of teaching that involves tacit knowledge including on-the-fly adjustments that come from experience.

Nonetheless, the dissemination models for implementing evidence-based instruction assume that the research-paper protocol, the best-practices guideline document, or the workshop, all of which transfer explicit knowledge, will suffice for implementing effective practice. This approach has included a plethora of websites 
and so-called handbooks for college teachers (Angelo \& Cross, 1993; Barkley, 2009; Barkley, Cross, \& Major, 2014) that list dozens of instructional options in a format that is reminiscent of the cookie recipe contemplated at the beginning of this essay. But, how much tacit knowledge - analogous to properly stirring the cookie dough is actually required in order to obtain the desired results?

I suggest, as well, that without tacit knowledge of teaching methods there is an increased likelihood of making substitutions or taking short cuts that limit, or perhaps even negate, the effectiveness of the intervention; analogous to using margarine instead of butter and speeding up the cooking time at a higher baking temperature. Without the subjective, experiential tacit knowledge of enacting an innovation, prior experiences and objectives may lead to ineffective implementation despite the explicit knowledge of the intervention. For instance, in his metadata report on the impact of interactive engagement versus lecture in physics, Hake (1998a) concluded that limited skills of the teacher to promote effective interactivity among students (arguably acquired as tacit knowledge from experience or observation) accounted for the few unsatisfactory results using active learning even when the instructor had explicit knowledge of the pedagogical methods and materials.

Turpen and Finkelstein's (2009) observational study of different physics professors using a well described active-learning strategy in large-enrollment classes - peer instruction with audience response systems, aka "clickers" (Mazur, 1997 ) - is an informative example of how varying tacit knowledge leads to variable implementation of a pedagogical innovation. Despite the simplicity of the method as an explicitly described procedure, Turpen and Finkelstein (2009) found that each professor implemented the method in a different way with recognizable disparate learning opportunities for students. The authors attributed these different instructional implementations "to how instructors use their knowledge of educational innovations and situational constraints to arrive at practical decisions in the moment-to-moment demands of the classroom" (p.14); clearly representing the intersection of tacit knowledge with the explicitly conveyed knowledge of the method. Notably, not all of the resulting variations from the "normal" implementation of peer instruction were viewed as negative by Turpen and Finkelstein (2009) who noted that their classroom observations opened windows on new research questions.

Differential tacit knowledge for implementing an explicitly described innovation may be a significant factor in the highly varied results for such innovations in the literature and may also influence the persistence of a new user. If the "recipe" for implementing a pedagogical innovation is dependent on the tacit knowledge of an "expert cook" (aka, experienced innovating teacher, SoTL researcher) then the willing, but under-knowledged teacher, and his or her students, may wind up with frustration that leads to abandoning an approach that has shown high value in a different context (e.g., with a different "cook" in a different "kitchen").

\section{The Competent Diagnosis Problem}

I propose that the second core implementation problem is illustrated by our two baking experiences. Specifically, the difference in our abilities to diagnose what might have gone wrong with the implementation of the cookie recipe. In the first situation, the baker was not only missing important tacit knowledge but gave up because of an inability to see what might be corrected in order to obtain a desired outcome. The baker in the second story, in contrast, recognized potential flaws in execution that impaired success but could be remedied. Short cutting and substitutions in the implementation of teaching innovations can have similar impacts and can only be avoided, or perhaps in some cases competently executed, if the teacher possesses sufficient foundational theoretical knowledge of learning processes. Educational researchers are more successful at increasing student 
learning through innovation than are colleagues who receive the intervention by handoff from the expert (Pollack \& Finkelstein, 2008). Therefore, Andrews, Leonard, Colgrove, and Kalinowski (2011) suggest that the effectiveness of active learning may be biased in the literature by the propensity of science-education researchers to publish their results. "We are concerned the impressive learning gains documented in the active-learning literature may not be typical of what typical instructors are likely to obtain" (p. 395).

In his detailed case study of a willing-to-change, but largely unsuccessful, faculty member, Charles Henderson (2005) provides a basis for the importance of competent diagnosis. The instructor drew most of his teaching innovations from external sources (along with his own ideas) but demonstrated only "awareness knowledge" of some of the selected techniques. By not endeavoring to obtain stronger explicit and tacit knowledge for these approaches, he not only missed opportunities but also modified some of the techniques without understanding why these innovations generated greater learning in their intended forms. Arguably, a significant part of this implementation problem was that the descriptions of the techniques were not grounded in explanations for why the techniques succeeded or what procedural components were essential and should not be modified or left out (Henderson, 2005). If the professor had greater knowledge of the theoretical underpinnings of the techniques, akin to our second baking experience, then he or she may have been able to determine the value of following the prescribed recipe or where a substitution or short cut would be acceptable or even represent a further beneficial extension of the method.

Perhaps one of the greatest problems with implementing interactive learning techniques is confident teacher understanding of group-learning dynamics. Proponents of small-group learning pointed out long ago (e.g., Johnson, Johnson \& Holubec, 1984) that simply putting students into groups will not assure effective interactive learning. Nonetheless, in my faculty-development experience many instructors give little, if any, thought to evidence-based approaches for creating groups, assuring positive interdependency of group learning, individual accountability to a group, or the likely necessity of team-building activities. Henderson (2005) noted this deficiency of understanding as a critical problem for the physics professor described above. Lou, Abrami, and Spence (2000), in a metaanalysis of small-group learning in $\mathrm{K}-12$ and higher-education settings, concluded that the most important factors determining student achievement from small-group learning are instructor knowledge of methods and design of problems, and how the groups are constructed, which points to the importance of teacher knowledge of methods that go beyond simple recipes.

The differential impact of instructor interaction with groups and how groups of students learn together appears dramatically in a recent study (Daubenmire et al., 2015) of two professors teaching chemistry with Process Oriented Guided Inquiry Learning (POGIL). Each instructor was experienced with POGIL and endorsed as a workshop facilitator for training others in this small-group learning approach. Nonetheless, students in one section scored nearly $30 \%$ higher on the conceptual knowledge component of a nationally validated examination. Data collected during the study showed the instructor of the higher-performing section commonly responded to student questions by probing with further questions, whereas the other instructor provided the requested answer. Quality of inquiry between students during group learning was also stronger for the higher-achieving class. Therefore, how one implements a method and how students are taught to engage with the method are critical determinants of learning outcomes.

Learning in groups depends as much on sociological phenomena as it does on cognitive processing. Groups go through developmental stages in order to function as an effective learning entity; which is a critical argument against a common practice to remake teams at least once during a course. In a particularly sobering study of group development in a classroom setting, Wheelan and Lisk (2000) tracked student teams that remained intact while completing a cohort-based curriculum that lasted more than one year. Five weeks into the curriculum nearly 
all of the teams still depended on the instructor to drive their learning activities and even after a year only half of the teams were truly working and learning together as groups of equal, trusting colleagues. The lesson of this story may be that we should not expect teams to function well within a 15-week semester unless we make teambuilding a priority. Nonetheless, many faculty feel ill-equipped to facilitate such activities or find them to be a "waste of time" in fast-paced, content-heavy courses.

Lastly, in this contemplation of the diagnosis problem is consideration of the fact that not all active learning is created equal. To some faculty the activelearning umbrella implies that if they have students do anything other than listen to lecture that there will be better learning and higher grades. I have undertaken classroom observations where activity was apparently added for the sake of making students active without considering how the students' work would actually generate the desired learning outcomes. In fact, time spent on active learning in class by different teachers does not correlate to learning gains (Andrews et al., 2011). Micki Chi's (2009; Chi \& Wylie, 2014) research that differentiates active learning based on overt learner behaviors, resulting in different levels of cognitive processing and different amounts of retained knowledge, is particularly informative. Using Chi's Interactive-Constructive-Active-Passive (ICAP) framework, it is possible for instructors to assess the likely match of teaching intentions with learning outcomes and to use student behaviors to see if the intentions were met.

\section{What Does a Scholarly Teacher Need to Know?}

Although few faculty choose to develop scholarship of teaching and learning into their portfolio, it is arguable (and in fact, expected at some institutions for tenure) that all faculty be scholarly teachers. Although not necessarily constructing structured research projects and disseminating results, as in the case of SoTL, scholarly teachers are reflective on their practice, observant for learning problems to explore, and cognizant of the research that is pertinent to resolving those problems and to fueling their reflection (Richlin, 2001). The scholarly teacher does not need to be the equivalent of an expert chef, but she or he should possess an informed and inquiring mind about teaching that permits problem diagnosis and solution analogous to our second baking experience.

Carl Bereiter (2014) proposes principled practical knowledge (PPK) as a means for closing the implementation gap between research and practice in education. In simplest terms, PPK combines the know-how of teaching with the know-why from research. Therefore, the procedural recipe for a teaching method is combined with sufficient theoretical background so that the user understands the principles underlying the technique. This theoretical foundation need not be extensive but focuses, instead, on the practical application of education research to teaching. By analogy, the cookie recipe provided explicit, practical knowledge but lacked context for why the recipe contained certain ingredients or procedures. This

To some faculty the activelearning umbrella implies that if they have students do anything other than listen to lecture that there will be better learning and higher grades.

explanatory knowledge, which is critical for improving or simplifying the recipe or even to implementing it for best results, is usually dependent on the principled knowledge of the baker. PPK includes the explanatory power of theory but has practical implementation, rather than explanation, as its purpose.

I suggest that PPK should be the basis for adoption of new pedagogies by scholarly teachers. In order to change teaching practice for consistency with research results explained by theory, the scholarly teacher needs to know why the innovations to their teaching are expected to work and not just how to do them. Diagnosing what went wrong when results fail to meet expectations, determining how to integrate different pedagogical strategies for maximum effect, and knowing 
how to simplify or make further innovative modifications to a new instructional design requires PPK.

One limitation remains, however, because PPK is explicit knowledge (Bereiter, 2014) and leaves the tacit-knowledge gap unfilled. Nonaka and von Grogh (2009) acknowledge that social practice is a necessary condition for acquiring tacit knowledge and for potentially converting it into explicit knowledge over time. College teaching is usually viewed as an individual

...the scholarly teacher needs to know why the innovations to their teaching are expected to work and not just how to do them. activity, taking place in the absence of colleagues. Classroom observation is typically viewed as a judgmental part of required performance evaluation. In contrast, the growth and exchange of tacit knowledge about teaching, and especially about the implementation of unfamiliar, novel approaches, requires socialization in the practice of teaching. Tacit knowledge of teaching methods, other than that gained from one's own experience, is acquired by watching others' practice, asking questions and offering suggestions. It requires observing classes not for the purpose of judging the teacher but to learn from the teacher. It requires communities of practice where faculty can directly share, create, and curate knowledge about teaching with one another.

\section{How Can SoTL Help?}

How does a college professor acquire the necessary principled practical knowledge to be a scholarly teacher? I argue that it is critical that instructional recipes for implementing evidence-based and research-informed pedagogies must come with the PPK attached for ready use. Faculty development workshops and consultations must include readily digestible explanations of why the methods work and what components are essential in order to expect success.

SoTL researchers can assist by being certain to both ground their research coherently in relevant theory and to translate the results into practical instructional application. Rooting educational research design and results in existing theory is not only an obviously essential research practice but it may also enhance adoption of new approaches. Persuading someone of a result, especially when they are skeptical of that result, is more likely when a cause for the outcome can be articulated rather than leaving the conclusion victim to claims of weakness due to anecdote or statistical relationships that are not explained by causality (Hoeken, 2001).

While grounding in theory and prior research it is also important that SoTL researchers move beyond their field. Considerable attention is given to disciplinebased education research (e.g., Singer, Nielsen, \& Schweingruber, 2012) and most SoTL scholars feel most confident with conducting their efforts within the comfort range of disciplinary content and epistemology. However, conducting SoTL work within disciplinary silos runs the risk of missing highly relevant learning-science contributions from other fields. For example, I recently surveyed ten articles on the use of audience response systems in medical education, published between 2003 and 2015. None of the articles acknowledge the research on peer instruction or use this method in the research design, despite the fact that peer instruction is the only clicker-mediated pedagogy that is backed up by extensive research (e.g., Crouch \& Mazur, 2001; Mazur, 1997; Smith et al., 2009). The disparate results reported on learning achievement in the medical-education research may, therefore, paint an unnecessarily negative perception of teaching with clickers by not informing medical educators of an effective pedagogical approach and perhaps the easiest interactive learning approach to implement in large lecture settings.

In conclusion, all teachers must be scholarly teachers. They must acquire both principled practical knowledge and tacit knowledge if they are to successfully implement research-based teaching innovations in their courses. With so many potential barriers to reforming undergraduate instruction it is essential that faculty 
willing to adjust their pedagogy not fail because they lacked essential knowledge to succeed. SoTL researchers can play a critical role by combining know-how and know-why knowledge that assures that the practicing teacher knows the essential components of the pedagogical intervention that cannot be removed or substituted without potential loss of learning fidelity. The know-why knowledge will be most persuasive if it is rooted in theory that explains the causes of learning and is broadly based across disciplinary contexts to assure generalizability beyond the single research case. Every teacher who is willing to try a new recipe should have the prospects of success and the ability to diagnose what went wrong during a failure with the potential to not only correct the error but to further innovate the method for even more positive results.

\section{Acknowledgements}

I am grateful for thoughtful reviews by Aurora Pun and Audriana Stark and for our many conversations in recent years that nurtured the ideas developed in this essay.

\section{References}

Andrews, T. M., Leonard, M. J., Colgrove, C. A., \& Kalinowski, S. T. (2011). Active learning not associated with student learning in a random sample of college biology courses. CBE Life Sciences Education, 10, 394-405. doi:10.1187/cbe.11-07-0061

Angelo, T. A., \& Cross, K. P. (1993). Classroom assessment techniques: $A$ handbook for college teachers. San Francisco, CA: Jossey-Bass.

Austin, A. E. (2011). Promoting evidence-based change in undergraduate education. Washington, DC: National Academy of Sciences. Retrieved from http://sites.nationalacademies.org/dbas se/bose/dbasse_071087

Barkley, E. F. (2009). Student engagement techniques: A handbook for college faculty. San Francisco, CA: Jossey-Bass.

Barkley, E. F., Cross, K. P., \& Major, C. H. (2014). Collaborative learning techniques: A handbook for college faculty (2nd ed.). San Francisco, CA: Jossey-Bass.

Bereiter, C. (2014). Principled practical knowledge: Not a bridge but a ladder. Journal of the Learning Sciences, 23(1), 4-17.

doi: $10.1080 / 10508406.2013 .812533$
Carnevale, A. P., Smith, N., \& Melton, M. (2011). STEM: Science, technology, engineering, mathematics. Retrieved from Georgetown University, Center on Education and the Workforce website: https://cew.georgetown.edu/ report/stem/

Chi, M. T. H. (2009). Activeconstructive-interactive: A conceptual framework for differentiating learning activities. Topics in Cognitive Science, $1(1)$, 73-105. doi:10.1111/j.17568765.2008.01005.x

Chi, M. T. H., \& Wylie, R. (2014). The ICAP framework: Linking cognitive engagement to active learning outcomes. Educational Psychologist, 49(4), 219-243. doi:10.1080/ 00461520.2014 .965823

Crouch, C. H., \& Mazur, E. (2001). Peer instruction: Ten years of experience and results. American Journal of Physics, 69, 970-977. doi: $10.1119 / 1.1374249$

Daubenmire, P. L, Bunce, D. M., Draus, C., Frazier, M., Gessell, A., \& Van Opstal, M. T. (2015). During POGIL implementation the professor still makes a difference. Journal of College Science Teaching, 44(5), 72-81. Retrieved from http://www.nsta.org/college/ 
Eagan, M. K., Stolzenberg, E. B., Berdan Lorzano, J., Aragon, M. C., Suchard, M. R., \& Hurtado, S. (2014). Undergraduate Teaching Faculty: The 2013-2014 HERI Faculty Survey Los Angeles, Higher Education Research Institute, UCLA.

Fixsen, D. L., Naoom, S. F., Blase, K. A., Friedman, R. M., \& Wallace, F. (2005). Implementation research: A synthesis of the literature. Retrieved from National Implementation Research Network website:

http://nirn.fpg.unc.edu/resources/imple mentation-research-synthesis-literature

Freeman, S., Eddy, S. L., McDonough, M., Smith, M. K., Okoroafor, N., Jordt, H., \& Wenderoth, M. P. (2014). Active learning increases student performance in science, engineering, and mathematics. Proceedings of the National Academy of Sciences, 111, 8410-8415.

doi:10.1073/pnas.1319030111

Hake, R. R. (1998a). Interactiveengagement methods in introductory mechanics courses. Retrieved from http://www.physics.indiana.edu/ sdi/IE M-2b.pdf

Hake, R. R. (1998b). Interactiveengagement versus traditional methods: A six-thousand-student survey of mechanics test data for introductory physics courses. American Journal of Physics, 66(1), 64-74. Retrieved from http://ajp.dickinson.edu/

Henderson, C. (2005). The challenges of instructional change under the best of circumstances: A case study of one college physics instructor. American Journal of Physics, 73(8), 778-786. doi:10.1119/1.1927547

Henderson, C., \& Dancy, M. H. (2007). Barriers to the use of research-based instructional strategies: The influence of both individual and situational characteristics. Physical Review Special Topics - Physics Education Research, 3(020102), 1-14.

doi:10.1103/PhysRevSTPER.3.020102
Henderson, C., \& Dancy, M. H. (2008). Physics faculty and educational researchers: Divergent expectations as barriers to the diffusion of innovations. American Journal of Physics, 76(1), 7991. doi:10.1119/1.2800352

Hoeken, H. (2001). Anecdotal, statistical, and causal evidence: Their perceived and actual persuasiveness. Argumentation, 15, 425-437. Retrieved from http://link.springer.com/ journal/10503

Hora, M. T. (2012). Organizational factors and instructional decisionmaking: A cognitive perspective. The Review of Higher Education, 35(2), 207235. doi:10.1353/ rhe.2012.0001

Johnson, D. W., Johnson, R., \& Holubec, E. (1984). Cooperation in the classroom ( $1^{\text {st }}$ ed.). Edina, MN: Interaction Book Company.

Kober, N. (2015). Reaching students: What research says about effective instruction in undergraduate science and engineering. Retrieved from The National Academies Press website: http://www.nap.edu/catalog.php?record _id $=18687$

Lou, Y., Abrami, P. C., \& Spence, C. (2000). Effects of within-class grouping on student achievement: An exploratory model. Journal of Educational Research, 84(2), 101-112. doi: $10.1080 / 00220670009598748$

Mazur, E. (1997). Peer instruction: A user's manual. Upper Saddle River, NJ: Prentice Hall.

McCrickerd, J. (2012). Understanding and reducing faculty reluctance to improve teaching. College Teaching, $60(2)$, 56-64. doi:10.1080/87567555.2011.633287

Nonaka, I., \& von Krogh, G. (2009). Perspective: Tacit knowledge and knowledge conversion: Controversy and advancement in organizational knowledge creation theory. Organization Science, 20(3), 635-652. doi: $10.1287 /$ orsc. 1080.0412 
President's Council of Advisors on Science and Technology. (2012). Engage to excel: Producing one million additional college graduates with degrees in science, technology, engineering, and mathematics. Washington, DC: Executive Office of the President. Retrieved from http://files.eric.ed.gov/fulltext/ED54151 1.pdf

Pollock, S., \& Finkelstein, N. (2008). Sustaining educational reforms in introductory physics. Physical Review Special Topics - Physics Education Research, 4(1) (010110), 1-8. doi:10.1103/PhysRevSTPER.4.010110

Richlin, L. (2001). Scholarly teaching and the scholarship of teaching. New Directions for Teaching and Learning, 2001(86), 57-68. doi:10.1002/tl.16

Seymour, E. (2002). Tracking the processes of change in US undergraduate education in science, mathematics, engineering, and technology. Science Education, 86, 79105. doi: 10.1002/ sce. 1044

Singer, S. R., Nielsen, N. R., \& Schweingruber, H. A. (2012). Disciplinebased education research: Understanding and improving learning in undergraduate science and engineering. Retrieved from The National Academies Press website: http://www.nap.edu/catalog.php?record _id $=13362$
Smith, M. K., Wood, W. B., Adams, C. K., Wieman, C. E., Knight, J. K., Guild, N., \& Su, T. T. (2009). Why peer discussion improves student performance on in-class concept questions. Science, 323(5910), 122124. doi: 10.1126/science. 1165919

Sunal, D. W., Hodges, J., Sunal, C., S., Whitaker, K. W., Freeman, L. M., Edwards, L., ... Odell, M. (2001). Teaching science in higher education: Professional development and barriers to change. School Science and Mathematics, 101(5), 246-257. doi: 10.1111/ j.1949-8594.2001.tb18027.x

Turpen, C., \& Finkelstein, N. D. (2009). Not all interactive engagement is the same: Variations in physics professors' implementation of peer instruction. Physical Review Special Topics - Physics Education Research, 5(020101),1-18. doi:10.1103/ PhysRevSTPER.5.020101

Wheelan, S. A., \& Lisk, A. R. (2000). Cohort group effectiveness and the educational achievement of adult undergraduate students. Small Group Research, 31(6), 724-738. doi: $10.1177 / 104649640003100605$

Gary A. Smith is a faculty developer and faculty member at the University of New Mexico in Albuquerque, New Mexico. He was the founding director of the Office of Support for Effective Teaching on UNM's main campus and currently directs the Office for Medical Educator Development in the School of Medicine. A faculty member in UNM's Department of Earth and Planetary Sciences for 28 years, Gary moved his faculty shingle to Organization, Information, and Learning Sciences in Fall 2015. He is also a principal investigator in STEM Gateway, a multi-year, multipronged effort, funded by the US Department of Education, to improve graduation of Hispanic and low-income STEM majors at UNM. His scholarly contributions range from more than 80 articles and book chapters in geoscience, to co-authorship of an introductory geology textbook, to publications and national meeting workshops and addresses involving classroom action research, student resistance to learnercentered instruction, and the situated cognition of faculty learners. 